\title{
A Ocupação: o direito à moradia e sua narrativa na literatura de Julián Fuks
}

\section{Astréia Soares ${ }^{1}$}

Janderson Silva ${ }^{2}$

\section{Resumo}

O artigo parte da narrativa literária de Julian Fuks, em seu livro A Ocupação, que retrata a luta dos chamados sem teto pelo direito à moradia em São Paulo, maior cidade do Brasil. A perspectiva do escritor é cotejada com os princípios do direito à moradia e à função social da propriedade. Estabelece como tema central verificar as possíveis relações entre direito e literatura brasileira contemporânea desenvolvendo uma análise interdisciplinar do fenômeno jurídico da ocupação a partir de texto literário, em busca de novas possiblidades de compreensão do direito sobre as representações dos chamados sem-teto.

Palavras-chave: Narrativa literária; Direito à moradia; Sem teto; Função social da propriedade; Ocupações.

Occupation: the right to housing and its narrative in Julián Fuks' literature

\begin{abstract}
The article starts from Julian Fuks' literary narrative, in his book A Ocupação, which portrays the struggle of the so-called homeless for the right to housing in São Paulo, largest city in Brazil. The writer's perspective is collated to the principles of the right to

\footnotetext{
${ }^{1}$ Astréia Soares é graduada em Ciências Sociais e mestre em Sociologia da Cultura pela UFMG. É doutora em Humanidades/Sociologia pelo PPGSA/IFCS da UFRJ. É professora titular da Universidade Fumec em cursos de graduação e no Programa de Pós-graduação em Direito. Coordena o grupo de pesquisa Comunicação, Cultura e Mudança Social. Contato: astreiasoares@gmail.com

${ }^{2}$ Janderson Silva é graduado em Comunicação/Jornalismo pela Universidade Fumec, mestrando em Comunicação pela UFOP e membro do Grupo de Pesquisa em Mídia e Interações Sociais (Giro) do PPGCOM. Contato: silva2janderson@gmail.com
} 
housing and the social function of property. It establishes as central theme to verify the possible relations between law and contemporary Brazilian literature by developing an interdisciplinary analysis of the legal phenomenon of occupation based on a literary text, in search of new possibilities for understanding the law on the representations of the socalled homeless.

Keywords: Literary narrative; Right to housing; Homeless; Social function of property; Occupations.

\section{Introdução}

Este artigo resultou de pesquisa sobre direito público, no campo do direito urbanístico, mais especificamente no que tange ao direito à moradia e à função social da propriedade. Para isto, estabeleceu como tema central verificar as possíveis relações entre direito e literatura brasileira contemporânea, que serão discutidas a partir das atuais ocupações de imóveis nas grandes cidades do país.

Os objetivos desta proposta foram os de desenvolver uma análise interdisciplinar do fenômeno jurídico da ocupação a partir de texto literário; contribuir com as pesquisas jurídicas que usam a literatura como recurso complementar; apresentar novas possiblidades de compreensão do direito sobre as representações dos chamados sem-teto.

Entendemos que tal proposta se justifique por se situar na intersecção entre o direito e a literatura, ponto em que encontramos importantes contribuições para a formação de um olhar mais amplo sobre os fenômenos jurídicos. O cotejamento entre estes dois campos torna-se, portanto, uma investida pertinente na medida em que apresenta novas perspectivas de reflexão, ancoradas nas possibilidades de compreensão da realidade que a ficção nos oferece. O fazer jurídico e a narrativa literária são instâncias importantes para a construção social da realidade, seja ela concreta ou simbólica. Exprimem-se por meio de suas linguagens, formando um conjunto de saberes e modos de ver o mundo de uma dada cultura. Além disto, reputa-se que os principais problemas de nossa época não se resolverão a partir de abordagens disciplinares, as quais já 
demonstraram sua limitação, o que justifica a busca de estudos interdisciplinares, ainda que introdutórios. O exercício de aproximação da ciência jurídica da narrativa literária pode estimular a revisão de posturas no direito que são tradicionais e condicionadas pelo formalismo.

Esta pesquisa seguiu a metodologia de revisão de literatura e de análise de narrativa, estratégias que se mostraram pertinentes para se discutir as ocupações, questão complexa e cercada de conflitos no campo jurídico. Promoveu-se, assim, o cotejamento da vertente jurídica sobre a função social da propriedade e sobre o direito à moradia, com a narrativa do escritor Julián Fuks no seu livro A Ocupação, publicado pela Companhia das Letras, em 2019.

Julián Fuks é um jovem escritor, nascido na Argentina e criado em São Paulo, que acumula atividades também no jornalismo e na crítica literária. Tendo sido escolhido pela prestigiosa revista britânica Granta como um dos vinte melhores jovens escritores brasileiros, acumula prémios literários como Jabuti e Saramago. O livro A Ocupação resultou de um patrocínio e teve tutoria do escritor moçambicano Mia Couto. Estas breves referências sobre o autor e sua obra são expostas aqui como justificativa da escolha de seu livro para promovermos o cotejamento entre direito e literatura no caso das ocupações, a fim de evidenciar as narrativas desses dois campos sobre o direito de ocupar, o direito à moradia e a função social da propriedade.

Entendemos que, ao abordarmos um escritor que figura entre os mais importantes da literatura brasileira jovem, colocamos em pauta a importância de se pensar questões do Direito Urbanístico por uma trilha interdisciplinar. No caso, a literatura de Fuks, de caráter autoficcional, escrita em uma linguagem direta e praticamente desprovida de lirismo (o que não significa que seja uma narrativa emocionante) que coloca o leitor diante de representações sobre os sem-teto as quais superam, por sua profundidade no trato das questões humanas, outras representações encontradas em alguns discursos estritamente jurídicos ou naquelas articuladas pela grande mídia.

Partindo desse pressuposto, esperamos que este trabalho possa contribuiu para ampliar o debate acerca dos pontos de convergência e de complementaridade entre o direito e a literatura. Ele foi articulado em três eixos: o direito à moradia, a narrativa 
literária e as representações dos sem-teto no discurso dos moradores da ocupação do Hotel Cambridge, em São Paulo, retratados por Julián Fuks.

O autor tem se caracterizado por construir histórias a partir de narrativas múltiplas, o que é também o caso do romance A Ocupação, que aborda o ato de "ocupar" em suas diferentes formas. Este artigo, entretanto, irá assumidamente contrariar o escritor optando por um recorte analítico que recairá exclusivamente sobre as representações que ele nos apresenta dos moradores do antigo Hotel Cambridge, edifício do centro da cidade de São Paulo que ficou abandonado por oito anos até ser ocupado pelo Movimento Sem Teto do Centro - MSTC, em 2012. Estima-se que a ocupação Cambridge abrigue cerca de 170 famílias, compondo um número aproximado de 500 pessoas e se constituindo como uma das maiores ocupações latino-americanas.

O que se pode vislumbrar a partir da narrativa de Fuks é a urgência de justiça no que se refere ao direito à moradia nas grandes cidades brasileiras e como a busca por este direito se expressa na narrativa ficcional.

\section{Direito à Moradia}

Neste lugar que chamamos hoje de território brasileiro compartilhamos do consenso histórico de que os primeiros registros da terra se deram após o estabelecimento das Capitanias Hereditárias com as doações de Sesmarias, por volta de 1534 (VARELA, 2005). Deu-se aí o início das escrituras de propriedade como documentos cartoriais, no contexto colonial no qual a igreja estava oficialmente atrelada ao Estado. A separação ente igreja e Estado só ocorreu formalmente após a Proclamação da República, em 1889.

A função social da propriedade, todavia, entra na pauta da sociedade brasileira como um tema de interesse das igrejas, atrelado também as esferas política e econômica da sociedade, surgindo brevemente na Constituição de 1824 e, mais explicitado, na Constituição de 1891, mais de 300 anos após os primeiros registros de propriedade feitos pela colônia (https://jus.com.br/artigos/67119/a-funcao-social-da-propriedade-nobrasil\#). Antes da Constituição de 1988, o tema foi tratado no adento sobre a função social da propriedade, no texto constitucional de 1946, que definia o bem-estar social como condição para o uso da propriedade e na Constituição Federal de 1969, com a definição 
de meios e normas para a promoção do fim social da propriedade. Com a Constituição de 1988, ganha destaque o artigo 182:

Art. 182. A política de desenvolvimento urbano, executada pelo poder público municipal, conforme diretrizes gerais fixadas em lei, tem por objetivo ordenar o pleno desenvolvimento das funções sociais da cidade e garantir o bem-estar de seus habitantes (BRASIL, 1988).

O Estatuto da Cidade, lei federal brasileira $n^{\circ} 10.257$, aprovada em 2001, se notabiliza como um marco legal avançado, que vem consolidar a construção de uma nova ordem jurídico-urbanística iniciada com a Constituição de 1988 (ALFONSIM et. al., 2016). Segundo Betânia Alfonsim et.al. (2016), o Estatuto da Cidade representa uma conquista para o país no sentido da previsão de

efeitos jurídicos concretos para o desatendimento do princípio da função social da propriedade e introduziu o direito à cidade no ordenamento jurídico pátrio. No entanto, a nova ordem jurídico-urbanística parece conviver, ainda hoje, com a antiga ordem civilista, aqui denominada de "modelo proprietário", paradigma comprometido com uma concepção de direito de propriedade de caráter absoluto, exclusivo, individual e perpétuo (ALFONSIM et. al., 2016, p.423).

A observação de Alfonsim et.al. quanto à uma tendência jurídica brasileira de se voltar para o caráter absoluto do direito de propriedade, muito mais do que para a garantia do bem-estar dos moradores da cidade - conforme estabelecido no texto constitucional corrobora a discussão que faz a arquiteta e urbanista Emília Maricato (2010) sobre o Estatuto da Cidade. Segundo a autora, a lei não seria resultado de um consenso sobre a gestão da cidade obtido estritamente nas esferas jurídicas, mas sim conquista de décadas de luta social protagonizada por diversos movimentos populares, entidades profissionais, setores políticos progressistas, acadêmicos, ONGs, dentre outros, em luta por uma governança democrática da cidade, pela justiça urbana e pelo equilíbrio ambiental.

Entretanto, no sentido de representar a busca por justiça social feita pelos movimentos sociais organizados, Maricato (2010, p.5) pondera:

o texto legal, embora fundamental, não é suficiente para resolver problemas estruturais de uma sociedade historicamente desigual na qual os direitos, como por exemplo o direito à cidade ou à moradia legal, não são assegurados para a maioria da população. Parte das grandes cidades brasileiras tem a maioria de sua população morando informalmente sem observação de qualquer lei ou plano urbanístico [...]. 
O ponto surpreendente desta questão não reside propriamente no fato de grande parte da população das grandes cidades brasileiras morar informalmente, alijada de elementos básicos da infraestrutura urbana, uma vez que esta situação se repete na maioria das sociedades periféricas do mundo. Conforme destaca Maricato, a questão central reside no fato do poder político e social insistentemente estar associado à propriedade patrimonial.

A Constituição Brasileira de 1988 transfere para aos municípios a competência para solucionar os conflitos fundiários, para gerir o uso, a ocupação e a propriedade das terras urbanas e imóveis e o planejamento das cidades. A perspectiva descentralizadora do Estatuto da Cidade significa um avanço com relação à política urbana anterior, menos democrática. Os planos diretores dos municípios passaram a ter a prerrogativa de definir tanto o conceito de propriedade não utilizada, quanto aquelas que serão submetidas às sanções previstas no Estatuto da Cidade. Contudo, tem sido recorrente que juízes ignorem a função da propriedade dando à propriedade privada um caráter de direito absoluto (MARICATO, 2010; ALFONSIM et.al.2016).

Tal prática coloca em questão o direito à moradia na sua dimensão de direito humano incluído como um os direitos sociais na Constituição brasileira de 1988. O jurista e urbanista Edésio Fernandes aponta que o direito de morar "deve ser entendido aqui em sentido amplo, isto é, o direito de todos viverem em condições dignas, adequadas e saudáveis, do ponto de vista urbanístico e ambiental (2006, p.19). O cenário nacional, neste sentido, tem sido muito mais de luta por direitos do que aplicação inconteste da lei, além da presença de incongruências estre o Estatuto da Cidade e os planos diretores de muitas cidades, fato importante de mencionar embora escape do foco principal deste trabalho.

O referido cenário de luta é protagonizado por alguns movimentos organizados, dentre eles o MSTC, que nos interesse em especial neste trabalho por ser apontado como responsável pela ocupação do Hotel Cambridge, retratada no romance escrito por Fuks. Trata-se de um movimento de mobilização de famílias para a reivindicação do direito à moradia. No site do MSTC (www.movimentosemtetodocentro.com.br) o movimento se auto representa pelo seguinte texto: 


\begin{abstract}
O Movimento Sem-Teto do Centro (MSTC) luta por esse direito fundamental, a moradia, principalmente na região central de São Paulo. Atende mais de duas mil pessoas, entre adultos, crianças e jovens. Moradia não se resume a propriedade física, mas também diz respeito à vida familiar, segurança, saúde, educação, mobilidade e convivência comunitária. Ter acesso a um lar é porta de entrada para uma série de outros direitos, pelos quais também lutamos (www.movimentosemtetodocentro.com.br).
\end{abstract}

Além disto, novamente tomando como referência o site do movimento, informam atuar junto ao governo e sociedade civil pelo "direito constitucional de acesso à moradia" e em prol da "correção" das "falhas cometidas há décadas pelo poder público, no que tange a distribuição urbanística e habitacional das metrópoles brasileiras" (www.movimentosemtetodocentro.com.br). As ocupações fazem parte das estratégias de luta por direito à moradia, questão paralela à intepretação do princípio de função social da propriedade (artigo 5 ${ }^{\circ}$, inciso XVIII da Constituição de 1988 regulamentado pelo Estatuto da Cidade).

O historiador, arquiteto e urbanista Tiago Lourenço comenta:

O conceito de ocupação urbana é fundamentado no arcabouço jurídico brasileiro, nele é valorizado o direito coletivo e difuso, valoriza- se a função social da propriedade, sobrepondo-se ao direito absoluto sobre a propriedade individual, que legitima deixá-la vazia sem cumprir sua função social caso o proprietário queira (2019,p.1652).

Os movimentos sociais pela habitação popular já ocuparam alguns edifícios no centro de São Paulo, trazendo para o debate sobre políticas urbanas o direito à moradia em áreas centrais, dotadas de infraestrutura e mais próximas às ofertas do mercado de trabalho. O hotel Cambridge foi ocupado em 2012. Um prédio considerado luxuoso, localizado em São Paulo, na avenida Nove de Julho e voltado, quando da sua inauguração nos anos 1950, para a elite paulistana. Foi fechado em 2002 devido à falência do empreendimento, desapropriado pela prefeitura em 2010 em razão de dívidas de IPTU que, 5 anos após a sua ocupação, regularizou-a no âmbito do programa Minha Casa Minha Vida.

O caso em pauta nos remete novamente à Fernandes (2018) em entrevista dada à BBC Brasil (https://www.bbc.com/portuguese/brasil-44028774), na qual cita dados do IBGE (do censo de 2010) que revelaram que havia, àquela época, 6,9 milhões de famílias sem casa e 6 milhões de imóveis vazios. O jurista não aponta esses dados com sugestão 
direita de solução do déficit habitacional com os imóveis desocupados, uma vez que defende políticas públicas diversas que facilitem a aquisição de moradia para a população de baixa renda e também invista em sistemas de propriedades coletivas, auxílio aluguel, dentre outras práticas. Para eles, o reconhecimento do direito à moradia é uma questão complexa do direito urbanístico brasileiro, que passa pela ausência de planejamento de onde os pobres vão viver e pela constatação paradoxal de que mesmo que os centros das cidades estejam perdendo população, a tendência de suprir habitação para as camadas mais pobres da sociedade tem sido o investimento em novas construções em regiões periféricas.

O discurso jurídico sobre o direito à moradia e a função social da propriedade vai muito além do eu foi exposto nesta sessão, mas nos permite avançar em uma abordagem interdisciplinar ampliando-o com vozes vindas da narrativa literária.

\section{Narrativas Literárias}

Nesta sessão apresentamos algumas reflexões sobre a literatura e suas narrativas, como um recurso necessário ao nosso intento de cotejar o campo jurídico com a abordagem ficcional sobre as ocupações de imóveis urbanos, fenômeno que marca a luta pelo direito à moradia em grandes cidades brasileiras.

Julián Fuks, o autor em pauta, nos apresenta um relato que, logo no primeiro momento podemos classificar como sendo de cunho político e que sugere que sua literatura, no caso do romance A Ocupação, carrega consigo um potencial de intervenção social, seja ele deliberado ou não.

A narrativa de caráter autoficcional solicita uma breve apresentação do termo, autofiction, no original, criado pelo escritor francês Serge Doubrovsky, em 1977, ainda que seja possível considerar que esse tipo de literatura vem de uma tradição ainda mais longa, desde a publicação dos Ensaios de Michel de Montaigne, em 1590 (“Assim, leitor, sou eu mesmo a matéria deste livro [...]”) ou de As Confissões, de Jean-Jacques Rousseau, em 1765 ("Quero mostrar aos meus semelhantes um homem em toda a verdade de sua natureza, e esse homem serei eu”), numa espécie de variante. Segundo Leyla PerroneMoisés (2016, p. 204), houvera na França um boom da publicação de livros cujo tema era o próprio autor nos anos 1980 e estes 
Não eram diários, porque não registravam os acontecimentos dia a dia, em ordem cronológica. Não eram autobiografias, porque não narravam a vida inteira do autor, mas apenas alguns momentos desta. Não eram confissões, porque não tinham nenhum objetivo de autojustificação e nenhum caráter purgativo.

Ainda de acordo com Perrone-Moisés, haveria na autoficção uma força narrativa da ordem do reconhecimento de si pelo Outro pois coloca o eu narrativo em uma situação de comunicação com um leitor que pode buscar, na individualidade do escritor, possíveis semelhanças consigo mesmo, acessando o que faltava à sua existência como indivíduo. Ou seja, "na linguagem escrita, logo que o enunciado diz "eu", ele se desdobra em dois: aquele que enuncia no mundo real e aquele outro que passa a existir por escrito" (PERRONE-MOISÉS, 2016, p. 208).

As narrativas podem ser modos de nos conectar com os acontecimentos sem que necessariamente sejam experimentados por nós. O autor aponta que a experimentação do acontecimento pode, além do sentido transportado por meio do contexto, se colocar também para o leitor por meio da narrativa. Estas considerações vão ao encontro da reflexão de José Luiz Aidar Prado, (2010, p 65) ao indagar:

Para que as pessoas compram textos, principalmente de revistas e da televisão?
A resposta não é para se informar, mas: para se enquadrar, ao se informar, para
se localizar, para ter narrativas de enquadramento no mundo, para saber qual é
o meu mundo, como ele funciona, como eu posso pertencer melhor a esse que
já é o meu mundo. Que realidade é essa à qual pertenço e devo pertencer como
ser em devir que sou? Como eu me transformo para melhor ser esse que eu
gostaria de ser? Como entendo melhor o mundo?

Se aceitamos este pressuposto de Prado, as narrativas com seu potencial de enquadramento do mundo, são elementos importantes para observamos e entendermos melhor as concepções de direito e de justiça por uma das vertentes que lhe é tangencial: a literatura.

O filósofo francês Jean-François Lyotard (1986, p. 35-36) não atribui importância unicamente o saber científico, reconhece também a importância do saber narrativo. Para ele "o saber, em geral, não se reduz à ciência, nem mesmo ao conhecimento", mas "misturam-se às ideias de saber-fazer, de saber-viver, de saber escutar". Os saberes narrativos, ainda segundo o autor, "possuem autoridade por si mesmos" e têm nas diferentes maneiras de vivenciar/narrar o cotidiano suas formas de apreender novos 
saberes, encenando-os. Estes saberes, portanto, promovem diversas articulações entre os sujeitos e a sociedade em que vivem, amparados pela própria experiência.

Para Bruno Leal (2013 p. 28), narrar seria

estabelecer um modo de compreensão do mundo, de configurar experiências e realidades, de comunicar-se com o outro. As narrativas, portanto, encontramse difundidas por diferentes realidades e tempos históricos, têm claramente uma dimensão antropológica e envolvem tanto uma pragmática quando um conjunto de mediações diversas.

As mediações mencionadas por Leal são importantes modos de se compreender as narrativas. O autor indica ser um "modo de apreender o mundo", "de dar sentido à vida". Estas instâncias, assim como eventos, sentimentos, diálogos, se encontram dispersos no espaço e no tempo e possuem distintas maneiras de serem apreendidas e compreendidas, pois, "pertencem ao mundo dos sonhos, dos desejos, do passado, das expectativas de futuro (LEAL, 2013, p. 29). As narrativas possuem capacidades suficientes para reunir, conectar, proporcionar experimentação, fazer comunicar diferentes relações.

Na relação entre direito e literatura, devemos destacar que podemos aprender e experimentar narrativamente o que dizem de nós e do que nos cerca. Produzimos individual ou coletivamente narrativas e, desta forma, temos na literatura um modo de narrar "realidades". Tal afirmação nos leva a considerar que, ao organizar o que está disperso, as narrativas se tornam capazes, como aponta Leal (2013, p. 33) de "tornar a experiência humana apreensível, figurável, e, portanto, acessível, inteligível”. Essa possibilidade diz de um modo de se comunicar que é a própria narrativa de histórias que apreendemos do mundo, de nós e de outros. O autor nos mostra ainda que, apenas efetivamos essa movimentação se, primeiramente, nos colocarmos na condição de escuta de outros interlocutores para que aquilo que nos é contado, passado, passe a pertencer a nós, de modo a fazer constituir do que sou e do mundo que habito.

Leal (2013, p. 33) considera também não haver uma linearidade neste tipo de circuito comunicativo, pois, "o receptor não é o fim da narrativa, mas a condição para sua perpetuação". É a partir do que vivenciamos através do outro que ganhamos a capacidade de contar novas histórias, a partir do que recebo de fora em posição de leitor, que me transforma também como um narrador. 
É por isso que as narrativas constituem uma forma de saber tão importante e difundido. Seja sob forma de mito, de notícias, romances, fofocas, grandes narrativas científicas, narramos porque encontramos nesse movimento, nessa "síntese do heterogêneo" um modo de lidar com aquilo que nos escapa e desafia nosso entendimento, inclusive o científico-racional. Diante da morte, das questões fundamentais acerca do que nos acontece, de quem eu sou e de quem é o outro, por exemplo, produzidos histórias e assim solucionamos narrativamente aquilo que não podemos responder, mas com que temos de lidar constantemente. (LEAL, 2013, p. 34).

A narrativa opera como um complexo mecanismo que envolve esforços de linguagem para sua compreensão, pois, ao produzir uma representação, uma imagem do acontecimento narrado, não se gera um reflexo, mas um movimento que sucinta sobre outras realidades, outros mundos produzindo variados entendimentos. Portanto, tal como propõe Leal narrar "é uma atividade que se dá na e para a cultura, as tradições, as realidades histórico-sociais: é certamente um agir no mundo" (2013, p. 36-37).

Leal (2002) cita Silviano Santiago para quem a narrador pós-moderno é sempre um ficcionista, ainda que sua narrativa, como é o caso de A Ocupação, seja voltada para fatos reais. Aquilo que narra é sua experiencia do olhar que por si, é ficcional. Os escritores, portanto, se enquadrariam nesta condição de narradores, quer seja de fatos cotidianos e políticos, como Fuks faz em A Ocupação, quer seja de experiências abstratas.

As reflexões dos personagens que permeiam a narrativa de Fuks em A Ocupação compõem o contexto político que caracteriza o romance e desenham uma teia de significações em torno da luta pelo direito à moradia. Sebastián, uma espécie de alter ego do escritor é o narrador deste encontro entre a literatura e a luta coletiva por moradia, entre a literatura e vida, com suas histórias singulares e comoventes. São histórias abafadas que ganham voz a partir de uma literatura do presente, um presente no qual se vê amplas desigualdades, injustiça social, descaso com a condição humana. Ampliar essas vozes termina por ser um recado para a concepção de direito e justiça de que suas definições formais não alcançam os habitantes reais do luxuoso prédio que um dia recebeu o pomposo nome de Hotel Cambridge.

A literatura aqui faz soar uma polifonia abafada, um conjunto de vozes de sujeitos igualmente abafados e mantidos à margem de cidades cada vez mais polarizadas. Restanos perguntar o que esta literatura tem a nos dizer sobre a dignidade humana como um princípio absoluto e sobre o direito á moradia como uma condição desta dignidade. 


\section{Discurso dos Personagens: os sentidos de ocupar, morar e viver no Cambridge}

O personagem Sebastián, já apresentado aqui como alter ego do escritor de A Ocupação, é quem narra flashes das histórias de vida dos atuais moradores do edifício Cambridge. Há entre eles toda sorte de sem-tetos reunidos na capital São Paulo, inclusive migrantes e refugiados, estrangeiros em terras paulistanas. Assim como eles, Sebastián/Fuks se reconhece ser estrangeiro também entre aqueles a quem quer ouvir e ampliar suas vozes, pelas consideráveis diferenças de origem social. O autor, em carta ao escritor moçambicano Mia Couto escreve:

\footnotetext{
Estou escrevendo um livro sobre a dor do mundo, a miséria, o exílio, o desespero, a raiva, a tragédia, o absurdo, um livro sobre esta interminável ruína que nos cerca, tantas vezes despercebida, mas escrevo protegido por paredes firmes" (FUKS, 2019, p.108).
}

A menção às paredes firmes que protegem o narrador nos reporta para um amplo universo de diferenças sociais no que se refere à segurança, quer seja segurança tanto no sentido concreto, quanto simbólico. A segurança não é um direito distribuído igualitariamente e seu acesso esbarra nos limites que são impostos pela pobreza, dentre outras razões.

As vozes que Sebastián conta ouvir por detrás da porta enfileiradas em corredores que já foram do hotel de luxo aos poucos vão ganhando rostos. Nas palavras do narrador “ganhavam agora rostos visíveis, contornos tangíveis, gestos contundentes” (2019, p.24). Ganham também um nome, este nome pode ser Preta, Sandra, Antônio, Brito, Najati, Carmen, Rosa e correspondem às pessoas que se encontram atrás daquelas portas, ocupando os cômodos que hoje lhes serve precariamente de moradia, uma vez que não há segurança jurídica na condição em que se encontram.

O narrador hesita entre o atrevimento de bater nessas portas e o desejo de ouvir as histórias dos ocupantes e, mesmo diante de seus conflitos sobre sua condição de intruso, de ser ele mesmo um ocupante, vai paulatinamente se permitindo, e permitindo ao leitor, uma aproximação daquelas vidas tão desconhecidas. 
Um dos encontros se dá com Najati, refugiado Sírio que testemunhou as atrocidades do conflito em sua terra, que deixou devido às concretas ameaças à sua vida. A história de Najati é a história da guerra civil da Síria, dos milhares de mortos, de famílias desmanteladas e de vidas desgarradas. Veio tentar fincar suas raízes a milhares de quilômetros de onde deixou seus entes queridos e sua casa. Najati escreve sobre laranjais do seu quintal, sobre a prisão e sobre o que se transformou "um entre muitos a vagar pelo mundo com as mãos nos ouvidos, ele disse, a abafar com as mãos os ruídos das bombas que explodem ao longe que nunca cessam de explodir" $(2019$, p.16).

O narrador diz que conhecer a história de Najati deixou-o sem palavras: "que palavra impossível lhe daria algum alívio, um conforto estéril? Ou ele queria para a sua história um autor, era essa a sua esperança, o meu fim?” (2019, p.17). Mas, as palavras estão aí para nossa leitura, para que possamos conhecer uma situação a qual tão pouco acesso temos e com tão pouco cuidado nos é apresentada, em geral apresentada em estatísticas de mortos, feridos e números de refugiados.

A lei brasileira do refúgio certamente não corresponde ao trato social dado a muitos dos refugiados. Muito pouco ouvimos das vozes do que vivem em trânsito, em movimento contínuo. Sebastián se transmuta em um autor para a história de Najati:

\footnotetext{
O Brasil talvez tivesse sido a escolha errada, sobretudo pelo rumo que as coisas têm tomado, ele disse, mas estava feliz, se é possível dizer algo assim, de fazer parte de uma comunidade, e uma comunidade de luta contra o desatino que nos governa em toda parte. Algo pude entender aqui, seguiu, que, embora a opressão possa se alastrar de pais em país, conquistando continentes inteiros, também a resistência é expansiva, também ela atravessa fronteiras (2019, p.80).
}

Assim, com a história de Najati sabemos também sobre tantos refugiados em busca de um chão em terras brasileiras. Sabemos sobre os riscos que a humanidade corre diante do avanço de práticas violentas e sabemos também o que iguala este sírio aos outros sem-teto que ocuparam o Cambridge, a mesma condição humana: "Sentia que a coexistência pelas calçadas nos igualava, mesmo sem nos livrarmos da nossa origem, da nossa história $(2019$, p.81).

Atrás de uma das portas do que foi um dia uma propriedade abandonada no centro de São Paulo, vive hoje Rosa. O Nome da mulher que experimentou o desespero do 
desamor, do abandono afetivo e social, da ruína de uma vida e de uma casa. Que como tantas e tantos simplesmente saiu andando na esperança de se distanciar daquilo que tornava indigna a condição humana. Esta foi a trajetória de Rosa:

você pergunta por que vim parar aqui, eu não sei dizer, só sei dizer porque saí
de lá. Chegando na rodoviária, eu não tinha aonde ir, entrei no metrô e segui a
massa porque não tinha a quem seguir. Minha vida era um vazio, feita só do
que já não existia. Foi a Carmen quem me tirou da rua naquelas primeiras
noites duras de São Paulo, foi a luta quem tirou dentro de mim aquela mulher
morta. O caso é que eu cansei de ser ocupada, por homem, por rato, por larva.
Agora é a minha vez de ocupar, você não acha? Rosa, meu nome é Rosa (2019,
p.54).

Os efeitos de vagar pelas noites de uma megacidade como São Paulo é provavelmente mais sentido no caso das mulheres, cuja vulnerabilidade se registra em dados inaceitáveis de violência doméstica e feminicídio. A ocupação tirou Rosa da rua e do abandono social. Estar entre iguais na luta por moradia é ainda viver na incerteza, mas é viver junto e ter uma causa.

Se Rosa fugia do desespero e do desamor, Demétrio Paiva, um peruano ocupando o décimo quarto andar do Cambridge saiu um dia de Cuzco com o sonho de acertar, de conquistar com seu trabalho o reconhecimento que move a tantos de nós. Assim Sebastián descreve Demétrio: "um homem tão cansado quanto eu, braços caídos e ombros baixos: homem num banco de palha contra as paredes baldias de sua sala" $(2019$, p.62).

O cenário em torno de Demétrio é composto de um corredor entulhado de coisas, de rolos de tecido, de maquinas descartadas e do ruído incessante da máquina batendo no tecido. Demétrio é costureiro. Tentou a vida sem nenhuma sorte por alguns países da américa latina. Hoje, passa dias intermináveis costurando peças que vão lhe render alguns centavos e que serão vendidas por algumas centenas.

A história que conta a Sebastián se parece com o som repetitivo e monótona da maquina de costura: "falava com indiferença, suas palavras também máquinas, falava sem emoção, como se costurasse vezes demais o mesmo diálogo" (2019, p.63). Demétrio é, ele mesmo, uma história de frustração que "trocando a vida por mercadorias pobres" não conseguiu nada mais do que fugir continuamente. Não há volta para ele que, como muitos outros nas ruas das cidades, perderam seu passado por vergonha dos que ficaram para trás e aos quais anunciou um dia que buscaria vitórias simples como ter onde morar e o que 
comer. Não volta por pudor, por um sentido injusto de fracasso, porque as injustiças sociais o alcançaram primeiro.

O narrador da ocupação e de suas gentes encontra Ginia, que veio do Haiti acostumada ao anonimato da mulher negra. A tragédia do terremoto no Haiti a um só tempo levou sua filha, sua casa e sua história. Na tentativa de nova vida em São Paulo, Ginia é mais uma das ocupantes do Cambridge. Ela desconfia daquele narrador que ronda a ocupação, porque nunca se quis ouvir uma mulher negra. Com o terremoto do Haiti, ela pergunta se ele quer de empréstimo sua comoção e sua dor? O terremoto em 2010 que matou 300 mil pessoas no Haiti e deixou um milhão e meio de desabrigados não é para Ginia a maior tragédia de seu povo. A maior tragédia do Haiti, ela lembra, foi o colonialismo.

Ginia adverte o narrador sobre os livros e a vida: "sobre o que é o seu livro? Ponha algo assim, em palavras mais bonitas e mais certeiras que as minhas, podem ser as suas não tem problema. Mas ponha algo mais que a dor, algo mais que a desgraça, se quiser escreve qualquer coisa que valha a pena" (2019, p.73).

A moradia de Najati, Rosa, Demétrio, Ginia, de famílias compostas de crianças e adolescente é um caso de luta pela função social da propriedade. Não se vê naquele prédio outrora imponente, um hotel de luxo conforme observa o narrador desta história:

\begin{abstract}
não existia ali mais nenhum hotel, e, no entanto, ali resistia seu saguão imponente, suas paredes cobertas de cal, despidas de todo adereço, seu teto inatingível sobre a minha cabeça. Não existia mais nenhum hotel, no entanto suas escadas se erguiam degrau a degrau, pelas polidas pela fricção incessante dos dias. Não existia mais nenhum hotel, e, no entanto, suas portas escondiam uma infinidade de corpos tão firmes quanto o meu, suas portas filtravam vozes quase inaudíveis, vozes que me alcançam em pela marcha, vozes que me mantinham em movimento (2019, p.14).
\end{abstract}

Podemos nos perguntar também se há esperança na literatura para esses homens e mulheres em ruína e para tantos outros que lutam para ampliar a defesa do direito à moradia como uma condição da dignidade humana.

A literatura é um convite a conhecer, pela vertente da ficção, mais do que o pouco que sabemos sobre ocupar e ser ocupante. Um exemplo está no trecho do livro em que o autor descreve uma assembleia geral dos moradores na qual surgem questão práticas de 
alta relevância como a água que está barrenta, o tapume do fosso do elevador que não oferece segurança, Brito, o morador que ocupa um quarto no décimo andar, que teve sua perna quebrado em um acidente de trabalho. Questões que ele chama de "litania das urgências".

Na confluência entre ficção e realidade, vale apresentar Carmem Silva Ferreira, baiana que viveu nas ruas de São Paulo nos anos 1990 e se tornou líder do MSTC. Foi presa e absolvida em processo em que foi acusada de extorsão. Na assembleia relatada por Sebastián, ela interrompe a "litania das urgências" com sua voz em alerta: "a conjuntura é de retrocesso, de repressão, de perda de direitos. Não dá para se fechar aqui dentro e ficar debatendo, só na delicadeza, esses detalhes de estética” (2019, p.24).

O que Carmen tem em mente se revela a seguir, sobre uma noite como muitas e muitas outras, em que o poder público - aparentemente descumprindo a função social da propriedade, exigência da Constituição Brasileira de 1988 e homologada pelo Estatuto da Cidade (2001) - devolveu às ruas mais de 200 famílias destruindo em minutos o pouco que tinham.

o prédio permaneceu de pé, estático, vazio, indiferente, e ao chão foram as duzentas famílias que ali moravam, fugindo avenida afora com os colchões em cima das cabeças, a passar aquela madrugada, e as seguintes, e as seguintes, debaixo de um viaduto lotado de gente (2019, p.25).

Do outro lado estavam as viaturas policias, homens posicionados com seus altofalantes e suas ameaças em defesa da "coisa em si" que se disputava: "um prédio inválido, morto, nada mais que sua carcaça" (2019, p.97).

A voz da liderança representada aqui por Carmen também lança seu alerta: “a gente não vai ao chão sem luta, sem resistência" (2019, p.25), confirmado um lema que aparece nas referências dos militantes do MSTC: "Quem não luta está morto".

Na análise de Carmen: "eles nos querem vagabundos, nos querem bandidos, maltrapilhos, indigentes. Querem que nos falte tudo, país, terra, casas para viver, chão para morrer. Esse é o erro deles: não sabem que somos todos refugiados, não sabem com que força os refugiados se fincam na pedra, como chega fundo a raiz do desterro. Então, 
podem ir se preparando, porque vai te flor nascendo no concreto, e essa flor é vermelha (2019, p.25).

Ter uma causa comum é o que reúne no Cambridge militantes do MSTC e refugiados, porque sendo brasileiro ou estrangeiro, estão na mesma busca pela dignidade humana, são sujeitos coletivos em busca da efetivação de direitos reconhecidos constitucionalmente. Como pondera Carmen à Sebastián "se quer entender este lugar melhor, melhor não perder de vista a coletividade, melhor se juntar a nós na luta. Apareça na festa deste domingo, venha descansado, traga qualquer coisa para comer e algumas peças de roupa" (2019, p.83).

Com este convite, o narrador segue pelos corredores tão distintos das paredes firmes entre as quais cresceu e vive porque quer nos contar uma "história do nosso fracasso civilizatório.

\section{Considerações Finais}

Frequentemente somos testemunhas de cenas violentas protagonizadas pela polícia, e mostradas pela mídia, nas reintegrações de posse em ocupações. Estas imagens são também narrativas que nos indicam, dentre outras coisas, que os movimentos pelo direito à moradia são alvo de intensa resistência. Da mesma forma, é possível que haja um significativo desconhecimento de quem são esses sujeitos em busca do real sentido da dignidade humana.

A narrativa literária aqui pendula entre a expressão da curiosidade, da infiltração do narrador - como comenta Sebastián ao se descrever como um saqueador de histórias que rouba daquela gente sua $\mathrm{voz}$ - e a possibilidade de se abrir com ela um diálogo, como lhe disse Najati.

Ocupar surge para o leitor como um imperativo e uma urgência de tantas pessoas, aquelas chamadas de sem-teto, atores socias das penumbras de uma sociedade que os quer resignados. Que não os quer como agentes de mudanças políticas, nem ao menos do cumprimento de leis que os levassem a ocupar o lugar da dignidade. 
Na confluência entre direito e literatura, postulamos que a narrativa literária, ao ter como seu objeto demandas por justiça, oferece ao direito mais um discurso sobre o mundo. Sobretudo, um discurso dos que não são contemplados pelo o que deveria ser direito de todos e, de fato, vem sendo apenas um privilégio de poucos.

\section{Referências}

ALFONSIN, Betânia de Moraes et al. A ordem jurídico-urbanística nas trincheiras do Poder Judiciário. In: Direito \&Praxis. Rio de Janeiro, Vol. 07, N. 14, 2016, p. 421-453.

BRASIL. Constituição (1988). Constituição da Repúbica Federativa do Brasil. Brasília, DF: Senado Federal: Centro Gráfico, 1988.

FERNANDES, Edésio. A nova ordem jurídico-urbanística no Brasil. In: FERNANDES, Edésio; ALFONSIN, Betânia. Direito urbanístico: estudos brasileiros e internacionais. Belo Horizonte: Del Rey, 2006. p. 3-23.

FERNADES, Edésio. Brasil tem 6,9 milhões de famílias sem casa e 6 milhões de imóveis vazios, diz urbanista. Entrevista concedida a Fernanda Odilla; Nathalia Passarinho e Luís Barrucho. BBCNews, 07 de maio de 2018. Disponível em < https://www.bbc.com/portuguese/brasil-44028774>. Acesso em 13/09/2020.

FUKS, Julián. A ocupação. São Paulo: Cia das Letras, 2019.

LEAL, Bruno de Souza. A grande mídia brasileira e identidades LGBT: um retrato em 2008 In: Revista Académica de la Federación Latinoamericana de Facultades de Comunicación Social. ed. 84. 2013. Disponível em: <http://dialogosfelafacs.net/wpcontent/uploads/2015/84/84-Revista-Dialogos-A-grande-midia-brasileira-e-identidadesLGBT.pdf> . Acesso em: 13/03/2016.

LEAL, Bruno de Souza. Do testemunho à leitura: aspectos da evolução do narrador jornalístico, hoje. Biblioteca online de Ciências da Comunicação, 2002. Disponível em $<$ http://www.bocc.ubi.pt/pag/leal-bruno-narrador-jornalismo.pdf $>$. Acesso em 20 de set.2020.

LEAL, Bruno de Souza. Saber das narrativas: narrar. In GUIMARÃES, Cesar.; FRANÇA, Vera (org). Na mídia, na rua: narrativas do cotidiano. Belo Horizonte: Autêntica, 2006.

LYOTARD, Jean-Françoi. O pós-moderno. Rio de Janeiro: José Olympio, 1986.

LOURENÇO, Tiago Castelo Branco. Ocupações urbanas de Belo Horizonte: Oratio e "na Real". Anais XVI Simpósio Nacional de Geografia Urbana, 2019.

VARELA, Laura Beck. Das sesmarias à propriedade moderna; um estudo de história do direito brasileiro. Rio de janeiro: Renovar, 2005. 
MARICATO, Ermínia. O Estatuto da cidade periférica. In: CARVALHO, Celso Santos; ROSSBACH, Anaclaudia (Org.). O Estatuto da Cidade comentado. São Paulo: Ministério das Cidades : Aliança das Cidades, 2010.

MONTAIGNE, Michel de. Ensaios. São Paulo: Abril S. A. Cultural e Industrial, 1972.

PERRONE-MOISÉS, Leyla. Mutações da literatura no século XXI. São Paulo: Companhia das Letras, 2016.

PRADO, José Luiz Odair. Convocação nas revistas e construção do a mais nos dispositivos midiáticos. In: Matrizes, v. 3, p. 36-78, 2010.

ROUSSEAU, Jean-Jacques. As Confissões. Rio de Janeiro: Nova Fronteira, 2018. Versão para Kindle. 